\title{
New software for generation of typical meteorological year
}

\author{
Abdulsalam Ebrahimpour ${ }^{1, *}$ \\ ${ }^{1}$ Departament of Mechanical Engineering, Islamic Azad University,Tabriz Branch, Tabriz, P.O.Box 51589, Iran \\ *Corresponding author. Tel.: 98 9123060463; fax: 98411 3317146, E-mail addresses: Salam_ebr@yahoo.com
}

\begin{abstract}
The correct selecting of typical meteorological year is an important factor for accurate building energy simulation. In this study, the Sandia method has been applied to prepare the new TmyCreator software for selecting the proper data as the typical meteorological year (Tmy2). Also, the results of this new software have been compared with the available Tmy2 weather data file for two cities. It is found that, the results of TmyCreator software have good agreement with the old created Tmy2 weather data file for these cities.
\end{abstract}

Keywords: Typical meteorological year; Building energy simulations; Finkelstein-Schafer statistics

\section{Introduction}

The weather data is the most important factor for building energy simulation software. The hourly data of meteorological parameters such as solar radiation, dry bulb temperature, relative humidity, wind speed, atmospheric pressure and etc are usually needed to simulate building energy.

Many methods have been suggested to provide the typical meteorological year. Typical meteorological year has been presented in different types for examples Tmy2 (NREL 1995) and WYEC2 (ASHRAE 1997) in the United States and Canada and TRY (CEC 1985) in the Europe. The Tmy2 and WYEC2 typical weather years contain more solar radiation and illumination data than older formats such as Tmy (NCDC 1983), WYEC (ASHRAE 1985) and TRY (NCDC 1981).

From 1970 to 1983, Ashrae commissioned three research projects to represent weather year data for energy calculations (WYEC), which used the TRY format but included solar data (measured data, if available or calculated based on cloud cover and type). In the early 1990s, Ashrae began to update the WYEC data set. New WYEC data sets were listed in Tmy format, and calculated hourly illuminance data, data quality as well as source flags, were included [1].

Typical meteorological year has been obtained in various types and for different cities in the earth's surface. Apple L.S. Chan [2] reviewed various types of typical weather data sets in a paper and then the Finkelstein-Schafer statistical method applied to analyze the hourly measured weather data of a 25-year period (1979-2003) in Hong Kong. A. Kalogirou [3] presented the generation of a type 2 typical meteorological year (Tmy2) for Nicosia, Cyprus. Also, Joseph. C. Lam [4], Zhang Qingyuan[5] and T. N. Anderson[6] in the different researches, provided the various typical meteorological years based on different year periods and in many places of the Earth's surface. The author (A. Ebrahimpour[7]) in previous research, created the typical meteorological year data from the measured weather data of a 14-year period (1992-2005) in Bandarabass using Sandia method [8].

In spite of this fact, the majority energy simulation softwares use typical Meteorological Year, so the exact values are necessary in order to correct estimation of the building energy consumption 
at the year. In this study, the Sandia method [8] has been used to create the TmyCreator software. Using the TmyCreator software, the typical meteorological year can be select from the measured weather data of a available year period (such as 1961-2010) in a city. The result of TmyCreator software has been compared with the available Tmy2 weather data file for various cities such as Salt Lake City.

\section{Sandia method}

The Sandia method is an empirical approach that selects individual months from different years of the period of record. For example, in the case that contains 30 years of data, all 30 Januarys are examined and the one judged most typical is selected to be included in the Tmy. The other months of the year are treated in a similar manner, and then the 12 selected typical months are concatenated to form a complete year. Because adjacent months in the Tmy may be selected from different years, discontinuities at the month interfaces are smoothed for 6 hours on each side. The Sandia method selects a typical month based on nine daily indices consisting of the maximum, minimum, and means dry bulb and dew point temperatures; the maximum and mean wind velocity; and the total global horizontal solar radiation. For each month of the calendar year, five candidate months with cumulative distribution functions (CDFs) for the daily indices that are the closest to the long-term CDFs are selected. The CDF gives the proportion of values that are less than or equal to a specified value of an index. Candidate monthly CDFs are compared to the long-term CDFs by using the following Finkelstein-Schafer (FS) statistics for each index.

$$
F S=(1 / n) \sum_{i=1}^{n} \delta_{i}
$$

Where, $\delta_{\mathrm{i}}$ is absolute difference between the long-term CDF and the candidate month CDF at xi and $\mathrm{n}$ is the number of daily readings in a month.

Because some of the indices are judged more important than others, a weighted sum (WS) of the FS statistics is used to select the 5 candidate months that have the lowest weighted sums. The weighting factors listed in Table 1 for Tmy type.

$W S=\sum w_{i} F S_{i}$

Where, $w_{i}$ is weighting for index and $F s_{i}$ is $F S$ statistic for index.

All individual months are ranked in ascending order of the WS values. A typical month is then selected by choosing from among the five months with the lowest WS values the one with the smallest deviation from the long-term CDF. In Hall's original method, persistence structures characterized by frequency and run length of days are included. The persistence of mean dry bulb temperature and daily global horizontal radiation are evaluated by determining the frequency and run length above and below fixed long-term percentiles. For mean daily dry bulb temperature, the frequency and run length above the 67th percentile and below the 33rd percentile are determined. For global horizontal radiation, the frequency and run length below the 33rd percentile are also determined. The persistence data are used to select, from the five candidate months, the month to be used in the Tmy. The highest ranked candidate month in ascending order of the WS values that meet the persistence criterion is used in the TMY. Then, the 12 selected months were 
concatenated to make a complete year and smooth discontinuities at the month interfaces for 6 hours each side using curve-fitting techniques. [9 \& 10]

Table 1: The weighting factors in Sandia method

\begin{tabular}{l|c} 
Wearher index & weighting factor \\
\hline Maximum dry bulb temperature & $1 / 24$ \\
\hline Minimum dry bulb temperature & $1 / 24$ \\
\hline Mean dry bulb temperature & $2 / 24$ \\
\hline Maximum dew bulb temperature & $1 / 24$ \\
\hline Minimum dew bulb temperature & $1 / 24$ \\
\hline Mean dew bulb temperature & $2 / 24$ \\
\hline Maximum wind speed & $2 / 24$ \\
\hline Mean wind speed & $2 / 24$ \\
\hline Total horizontal solar radiation & $12 / 24$ \\
\hline Direct normal solar radiation & --
\end{tabular}

\section{Tmy2 selection procedure in TmyCreator software}

For using the TmyCreator software, The hourly measured weather data of Dry Bulb Temperature $\{C\}$, Dew Point Temperature $\{C\}$, Relative Humidity $\{\%\}$, Atmospheric Pressure $\{\mathrm{Pa}\}$, Wind Direction $\{$ deg $\}$, Wind Speed $\{\mathrm{m} / \mathrm{s}\}$, Global Horizontal Radiation $\{\mathrm{Wh} / \mathrm{m} 2\}$, Direct Normal Radiation $\{\mathrm{Wh} / \mathrm{m} 2\}$ and Diffuse Horizontal Radiation $\{\mathrm{Wh} / \mathrm{m} 2\}$ have been prepared.

In Sandia method, the hourly measured data of dry bulb temperature, dew point temperature and wind speed have been used to select the Tmy2. So, calculating the maximum, minimum, and mean dry bulb and dew point temperatures and the maximum and mean wind velocity during a day and total global horizontal solar radiation during a day have been based on hourly measured data in TmyCreator software.

Other remained data in the Tmy2 weather file has not been calculated and the default values of Energyplus document software have been used [11].

\section{The TmyCreator software}

To use the TmyCreator software (Figure 1) the hourly measured weather data must be prepared for the desired period (such as 1990-2010). Also, the hourly measured weather data are the Dry Bulb Temperature $\{\mathrm{C}\}$, Dew Point Temperature $\{\mathrm{C}\}$, Relative Humidity $\{\%\}$, Atmospheric Pressure $\{\mathrm{Pa}\}$, Wind Direction $\{\mathrm{deg}\}$,Wind Speed $\{\mathrm{m} / \mathrm{s}\}$, Global Horizontal Radiation $\{\mathrm{Wh} / \mathrm{m} 2\}$,Direct Normal Radiation $\{\mathrm{Wh} / \mathrm{m} 2\}$ and Diffuse Horizontal Radiation $\{\mathrm{Wh} / \mathrm{m} 2\}$. 


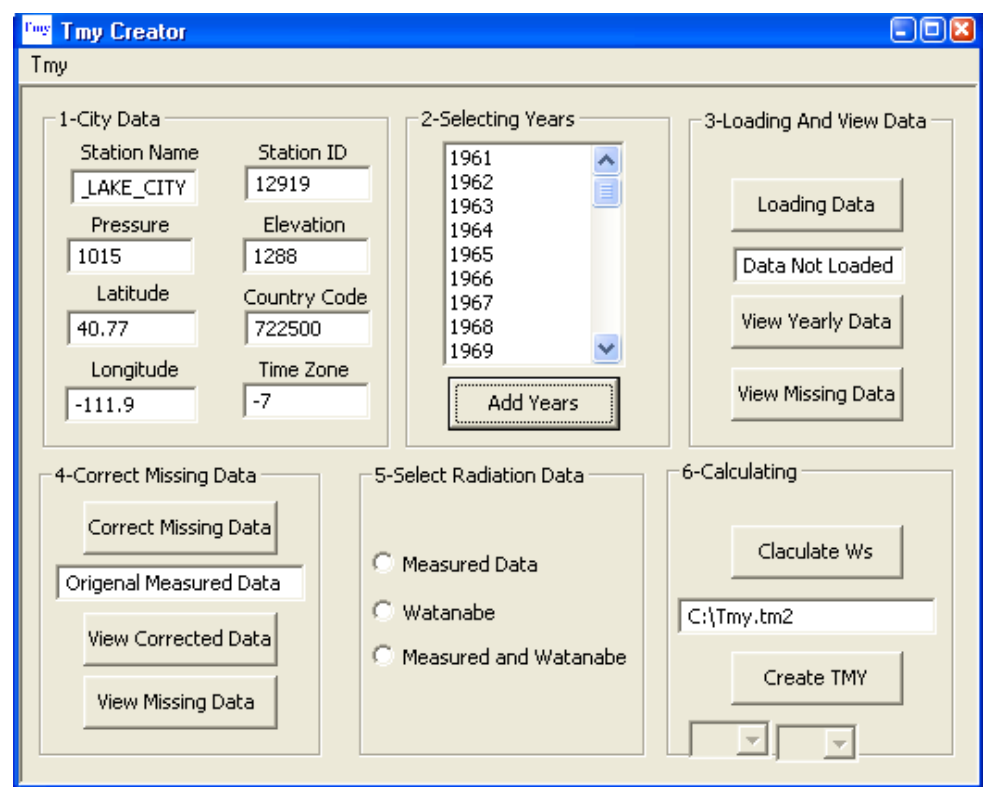

Figure 1: The TmyCreator software

\subsection{Correct Missing Data}

The TmyCreator software corrects the missing data using other available data as following method:

The missed data $=$ (the amount of after three hour+ the amount of before three hour)/2

\section{Validating the TmyCreator software}

To validating of the TmyCreator software two methods have been used. In the first method, the Tmy2 weather data for the two city of the USA have been created by TmyCreator software from hourly weather data and the created Tmy2 file have been compared with the created Tmy2 weather data by NREL ${ }^{1}$.

\subsection{Comparing the Tmy2 Weather file}

In the first stage, the 30 year period (1961-1990) hourly weather data for two city of the USA have been provided from the $\mathrm{NCDC}^{2}$ and $\mathrm{NSRDB}^{3}$ (for solar radiation data) and using this data the Tmy2 weather file have been created by TmyCreator software. Then the information about of selected year in the Tmy2 weather file created by TmyCreator software and NREL has been compared.

The Table 2 and 3 shows the number of not available hourly weather data for Abilene and Salt Lake City in USA in the year. It can be seen that the missing data for Abilene City is more than Salt Lake City.

The result of running the TmyCreator software using this hourly weather data for mentioned cities have been displayed in the Table 4 and 5 .

${ }^{1}$ National Renewable Energy Laboratory

${ }^{2}$ http://www1.ncdc.noaa.gov

${ }^{3}$ http://rredc.nrel.gov 
Table 2: number of not available hourly weather data for Abilene in the year

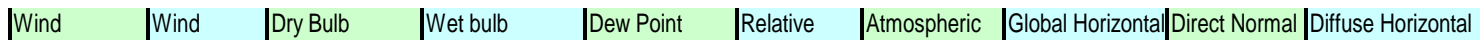

\begin{tabular}{|c|c|c|c|c|c|c|c|c|c|c|}
\hline Year & Direction $\{$ deg\} & Speed $\{\mathrm{m} / \mathrm{s}$ & Temperature $\{C\}$ & Temparature $\{C\}$ & Temperature\{C & Humidity $\{\%\}$ & Pressure $\{\mathrm{Pa}\}$ & Radiation & Radiation & Radiation \\
\hline 1961 & 981 & 2 & 2 & 2 & 2 & 2 & & & & \\
\hline 1962 & 665 & 2 & 2 & 2 & 2 & 3 & & & & \\
\hline 1963 & 702 & & & 1 & 1 & 1 & & & & \\
\hline 1964 & 227 & 4 & 4 & 4 & 4 & 4 & & & & \\
\hline 1965 & 5883 & 5836 & 5836 & 5837 & 5837 & 5836 & & & & \\
\hline 1966 & 5914 & 5840 & 5840 & 5840 & 5840 & 5840 & & & & \\
\hline 1967 & 5888 & 5840 & 5840 & 5841 & 5841 & 5840 & & & & \\
\hline 1968 & 5880 & 5840 & 5840 & 5840 & 5840 & 5840 & & & & \\
\hline 1969 & 5864 & 5840 & 5840 & 5840 & 5840 & 5840 & & & & \\
\hline 1970 & 5854 & 5840 & 5840 & 5841 & 5841 & 5840 & & & & \\
\hline 1971 & 5854 & 5840 & 5840 & 5840 & 5840 & 5840 & & & & \\
\hline 1972 & 5845 & 5840 & 5840 & 5840 & 5840 & 5840 & & & & \\
\hline 1973 & 166 & 149 & 151 & 156 & 157 & 2501 & & & & \\
\hline 1974 & 156 & 92 & 97 & 99 & 100 & 601 & & & & \\
\hline 1975 & 286 & 209 & 203 & 216 & 219 & 246 & & & & \\
\hline 1976 & 280 & 208 & 210 & 222 & 225 & 703 & & & & \\
\hline 1977 & 240 & 165 & 159 & 165 & 168 & 179 & & & & \\
\hline 1978 & 245 & 203 & 197 & 205 & 206 & 213 & & & & \\
\hline 1979 & 308 & 205 & 205 & 204 & 206 & 229 & & & & \\
\hline 1980 & 224 & 147 & 146 & 150 & 150 & 159 & & & & \\
\hline 1981 & 217 & 99 & 106 & 107 & 108 & 113 & & & & \\
\hline 1982 & 92 & 2 & 2 & 2 & 2 & 2 & & & & \\
\hline 1983 & 263 & 1 & 1 & 1 & 1 & 1 & & & & \\
\hline 1984 & 84 & 1 & & 1 & 1 & 1 & & & & \\
\hline 1985 & 108 & & & 1 & 1 & & & & & \\
\hline 1986 & 186 & & & & & & & & & \\
\hline 1987 & 233 & 1 & 1 & 1 & 1 & 2 & & & & \\
\hline 1988 & 209 & & & & & & & & & \\
\hline 1989 & 140 & 1 & & & & & & & & \\
\hline 1990 & 171 & & & & & & & & & \\
\hline
\end{tabular}

Table 3: number of not available hourly weather data for Salt Lake City in the year

\begin{tabular}{|c|c|c|c|c|c|c|c|c|c|c|}
\hline Year & $\mid \begin{array}{l}\text { Wind } \\
\text { Direction\{deg\} }\end{array}$ & $\left|\begin{array}{l}\text { Wind } \\
\text { Speed }\{\mathrm{m} / \mathrm{s}\}\end{array}\right|$ & \begin{tabular}{|l} 
Dry Bulb \\
Temperature $\{\mathrm{C}\}$
\end{tabular} & $\begin{array}{l}\text { Wet bulb } \\
\text { Temparature }\{\mathrm{C}\}\end{array}$ & $\mid \begin{array}{l}\text { Dew Point } \\
\text { Temperature\{C\}}\end{array}$ & \begin{tabular}{|l} 
Relative \\
Humidity $\{\%\}$
\end{tabular} & $\mid \begin{array}{l}\text { Atmospheric } \\
\text { Pressure\{Pa\} }\end{array}$ & \begin{tabular}{|l|} 
Global Horizontal \\
Radiation
\end{tabular} & \begin{tabular}{|c} 
Direct Normal \\
Radiation
\end{tabular} & \begin{tabular}{|l|} 
Diffuse Horizontal \\
Radiation
\end{tabular} \\
\hline 1961 & \begin{tabular}{|l|}
387 \\
\end{tabular} & 1 & 1 & 1 & 1 & 1 & & & & \\
\hline 1962 & 322 & & & & & & & & & \\
\hline 1963 & 296 & & & 2 & 5 & & & & & \\
\hline 1964 & 363 & 1 & & & & & & & & \\
\hline 1965 & 320 & & & & & & & & & \\
\hline 1966 & 190 & & 1 & & 1 & & & & & \\
\hline 1967 & 186 & & & & & 1 & & & & \\
\hline 1968 & 421 & & & & 8 & & & & & \\
\hline 1969 & 318 & & & 1 & 3 & & & & & \\
\hline 1970 & 301 & & & 12 & 12 & 12 & & & & \\
\hline 1971 & 159 & & & 1 & 1 & & & & & \\
\hline 1972 & 201 & & & & & & & & & \\
\hline 1973 & 210 & 1 & 1 & 1 & 1 & 1 & & & & \\
\hline 1974 & 195 & 1 & & 1 & 2 & & & & & \\
\hline 1975 & 309 & 1 & & & & & & & & \\
\hline 1976 & 350 & 6 & 2 & 2 & 7 & 1 & & & & \\
\hline 1977 & 301 & 91 & 78 & 75 & 91 & 80 & & & & \\
\hline 1978 & 285 & 13 & 7 & 3 & 14 & 6 & & & & \\
\hline 1979 & 269 & & 1 & & 2 & & & & & \\
\hline 1980 & 359 & & & & & & & & & \\
\hline 1981 & 258 & & & & & & & & & \\
\hline 1982 & 193 & & & & & & & & & \\
\hline 1983 & 217 & & & 1 & 1 & & & & & \\
\hline 1984 & 284 & & & & 2 & & & & & \\
\hline 1985 & 323 & 1 & 1 & 1 & 1 & 1 & & & & \\
\hline 1986 & 323 & 2 & 2 & 3 & 3 & 2 & & & & \\
\hline 1987 & 216 & & & 1 & 1 & & & & & \\
\hline 1988 & 179 & & & & & & & & & \\
\hline 1989 & 274 & & & 1 & 1 & & & & & \\
\hline 1990 & 409 & & & 1 & 1 & & & & & \\
\hline
\end{tabular}

Table 4: Compared result of TmyCreator software and available Tmy2 data by NREL for Salt Lake City 


\begin{tabular}{|r|l|l|l|}
\cline { 2 - 4 } \multicolumn{1}{c|}{} & City Name & Salt Lake & \\
\cline { 2 - 4 } \multicolumn{1}{c|}{} & & Name of years used by NREL & Name of years used by TmyCreator software \\
\hline 1 & JANUARY & 1976 & 1976 \\
\hline 2 & FEBRUARY & 1971 & 1973 \\
\hline 3 & MARCH & 1967 & 1987 \\
\hline 4 & APRIL & 1976 & 1976 \\
\hline 5 & MAY & 1989 & 1988 \\
\hline 6 & JUNE & 1968 & 1968 \\
\hline 7 & JULY & 1976 & 1976 \\
\hline 8 & AUGUST & 1973 & 1989 \\
\hline 9 & SEPTEMBER & 1972 & 1972 \\
\hline 10 & OCTOBER & 1967 & 1968 \\
\hline 11 & NOVEMBER & 1962 & 1962 \\
\hline 12 & DECEMBER & 1965 & 1965 \\
\hline
\end{tabular}

Table 5: Compared result of TmyCreator software and available Tmy2 data by NREL for Abilene City

\begin{tabular}{|c|c|c|c|}
\hline & \multirow[t]{2}{*}{\begin{tabular}{|c|} 
City Name \\
\end{tabular}} & \multicolumn{2}{|l|}{ Abilene TX } \\
\hline & & Name of years used by NREL & Name of years used by TmyCreator software \\
\hline 1 . & JANUARY & 1974 & 1974 \\
\hline 2 & FEBRUARY & 1980 & 1961 \\
\hline 3 & MARCH & 1961 & 1961 \\
\hline 4 & APRIL & 1969 & 1969 \\
\hline 5 & MAY & 1981 & 1981 \\
\hline 6 & JUNE & 1979 & 1979 \\
\hline 7 & JULY & 1974 & 1988 \\
\hline 8 & AUGUST & 1981 & 1970 \\
\hline 9 & SEPTEMBER & 1962 & 1970 \\
\hline 10 & OCTOBER & 1980 & 1980 \\
\hline 11 & NOVEMBER & 1977 & 1971 \\
\hline 12 & DECEMBER & 1967 & 1979 \\
\hline
\end{tabular}

In these tables the selected year for each month of the year by TmyCreator software and NREL have been showed. It can be seen that the TmyCreator software selected the years for 7 month like as selected year in NREL weather data for Salt Lake City and also selected the years for 6 month like as selected year in NREL weather data for Abilene City. Complete dissimilarity years selected for each month in the NREL file and the file produced by TmyCreator software is the following reasons:

1- As shows in Table 2 and 3, the missing data for these cities is more and not known that NREL How corrected the missing data when created the Tmy2 weather data file. The TmyCreator software corrects the missing data using other available data as following method :

The missed data = (the amount of after three hour+ the amount of before three hour)/2

2- Because the solar radiation data have important role in selecting the year of the Sandia method,

it not known that NREL used of hourly measured radiation data or predicted data.

So, we can say that the TmyCreator software is acceptable.

\section{Conclusions}

In this study, the Sandia method has been applied to prepare the new TmyCreator software for selecting the proper data as the typical meteorological year (Tmy2). Also, the results of this new 
software have been compared and it is found that, the results of TmyCreator software have good agreement with the old created Tmy2 weather data file. Using this software the Tmy2 weather file can be prepared for anywhere of the earth. The Tmy2 weather data file have been prepared for 6 city of IRAN (Tehran, Tabriz, Esfahan, BandarAbass, Shiraz, Boshehr and Yazd).

\section{References}

[1] Crawley D, Hand J, Lawrie L. Improving the weather information available to simulation programs. Washington, DC: US Department of Energy.

[2] L.S. Chan, T.T. Chow, K.F. Fong and Z. Lin, Generation of a typical meteorological year for Hong Kong, Energy Conversion and management,47 (2006), pp. 87-96.

[3] A. Kalogirou, Generation of typical meteorological year (Tmy2) for Nicosia, Cyprus, Renewable Energy, 28 (2003), pp. 2317-2334.

[4] C. Lam, C.M. Hui and L.S. Chan, A statistical approach to the development of a typical meteorological year for Hong Kong, Architectural Science Review, 39 (1986), pp. 201-209.

[5] Zhang Qingyuan, Joe Huang, Lang Siwei. Development of Chinese weather data for building energy calculations. In: 4th International conference on indoor air quality, ventilation and energy conservation in buildings, Changsha, Hunan, China, 2-5 October, 2001. p. 1211.

[6] Anderson TN, Duke M, Carson JK. A typical meteorological year for energy simulations in Hamilton, New Zealand. IPENZ engineering treNz 2007-003, ISSN 1177-0422.

[7] A .Ebrahimpour, M. Maerefat, A method for generation of typical meteorological year, Energy Conversion and Management, 51(2010), pp. 410-417

[8] J.M. Finkelstein and R.E. Schafer, Improved goodness-of-fit tests, Biometrika 58 (3) (1971), pp. 641-645.

[9] Hall I, Prairie R, Anderson H, Boes E. Generation of typical meteorological years for 26 SOLMET stations, SAND78-1601. Albuquerque, NM: Sandia National Laboratories; 1978.

[10] Marrion William, Urban Ken. User’s manual for Tmy2s typical meteorological years. National Renewable Energy Laboratory, US Department of Energy; 1995.

[11] EnergyPlus documentation, software. <http://apps1.eere.energy.gov/buildings/energyplus/> .

[12] J.A. Duffie and W.A. Beckman, Solar energy of thermal processes, John Wiley, New York (1980).

[13] The Climate Consultant [version 5] software [http://www.energy-design-tools.aud.ucla.edu]

[14] The HEED (Home Energy Efficient Design, http://www.energy-designtools.aud.ucla.edu/heed/)

[15] The eQUEST (Quick Energy Simulation Tool, http://www.doe2.com) software 